\title{
Karakteristik Iregularitas Infleksi Nominal Bahasa Arab, Studi Kasus pada Jamak Taksir
}

\author{
Zaqiatul Mardiah ${ }^{1}$, Afridesy Puji Pancarani ${ }^{1}$ \\ ${ }^{1}$ Prodi Bahasa dan Kebudayaan Arab, Fakultas Ilmu Pengetahuan Budaya, Universitas Al Azhar Indonesia, \\ Jl. Sisingamangaraja, Kompleks Masjid Agung Al Azhar, Jakarta Selatan 12110 \\ Penulis untuk korespondensi/E-mail: zaqiah@uai.ac.id
}

\begin{abstract}
Abstrak - Pada hakikatnya, di dalam ketidakteraturan ada pola yang teratur. Kajian ini hendak mencermati dan menemukan keteraturan pola dalam ketidakteraturan proses morfologis infleksi nominal bahasa Arab, jamak taksir. Bentuk-bentuk yang dinamis dan beragam pada perubahan bentuk singular menjadi plural dalam jamak taksir memiliki kecenderungan yang dapat dipetakan menjadi pola tertentu. Untuk memotret fenomena tersebut, kajian awal ini mengambil data dari kamus Arab-Inggris Hans Wher dari entri alif hingga kha', yang dibatasi pada ism tunggal yang berpola fa'lun, fi'lun, fi'latun, fi'a:lun, fu'latun, fa'alun, dan fa'latun. Dengan metode deskriptif kualitatif, masing-masing bentuk singular akan dicermati aspek fonologis dan semantisnya; yang menjadi bentuk plural dengan karakteristik fonologis dan semantik yang juga menjadi fokus perhatian. Kajian ini membenarkan tesis dari Pingker tentang pola-pola tidak teratur yang sebenarnya memuat keteraturan. Dalam riset ini, sebagian besar bentuk plural dari jamak taksir dapat diramalkan dengan melihat consonant order dari bentuk tunggalnya.
\end{abstract}

Abstract - Actually, there is a regular pattern in irregularities. This study was to examine and find the regularity patterns in the irregularities of the nominal inflection of morphological process of Arabic, jamak taksir. Dynamic and varied forms of morphological process from singular to plural in the jamak taksir have a tendency that can be mapped into certain regular patterns. To capture the phenomenon, this initial study took data from Hans Wher's Arabic-English dictionary from the Alif to Kha ' entry, which was confined to the singular ISM patterned fa'lun, fi'lun, fi'latun, fi'a:lun, fu'latun, fa'alun, and fa'latun. With qualitative descriptive methods, each singular form will be examined by the phonological aspect and its semantics; which became a plural with the phonological and semantic characteristics that also became the focus of attention. This study justifies the thesis of the Pingker on irregular patterns that actually load regularity. In this research, most of the plural form of the jamak taksir can be predicted by looking at the order consonant from the singular.

Keywords - Arabic broken plural, irregularity, inflection, phonological aspect.

\section{PENDAHULUAN}

I nfleksi nominal dalam banyak bahasa flektif dapat bersifat regular, dan dapat pula iregular. Beberapa bukti linguistis menunjukkan bahwa infleksi regular dan iregular banyak dipengaruhi oleh karakteristik morfofonologis dari bahasa itu [1]. Dalam bahasa Inggris, sufiks $-\mathrm{s}$ atau -es pada books dan boxes, merupakan kaidah reguler. Sufiks -u:na pada muslimu:na juga masuk dalam kategori jamak muzakkar salim (plural regular maskulin insani) dalam bahasa Arab. Penambahan sufiks -s atau -es untuk menandai bentuk plural dalam bahasa Inggris tersebut, tentu saja mengikuti aturan yang sifatnya mudah diramalkan, yaitu -s akan diimbuhkan pada nomina yang berakhiran konsonan selain frikatif, sedangkan -es akan diimbuhkan pada nomina yang diakhiri konsonan frikatif. Ada kaidah morfofonologis pada perubahan bentuk kata itu. Demikian pula dengan pembentukan plural maskulin insani dalam bahasa Arab. Sufiks -u:na hanya akan diimbuhkan pada nomina tunggal maskulin insani saja, dan dengan syarat nomina itu berfungsi sebagai subjek dalam kalimat. Ketika nomina tersebut berfungsi sebagai objek, maka sufiksnya pun akan berubah, yakni -i:na. 
infleksi nominal lainnya dalam bahasa Arab bersifat regular. Berikut adalah contoh jamak taksir.

Singular
/bahs/ $\rightarrow$ /buhu:
/dars/ $\rightarrow$ /duru:s/'pelajaran-pelajaran'
/qolam/ $\rightarrow$ /aqla:m/ 'pulpen-pulpen'
/yawm/ $\rightarrow$ /ayya:m/ 'hari-hari

Penelitian ini dilakukan untuk mempelajari karakteristik fonologis dan semantis pembentukan jamak taksir atau jamak takberaturan. Dari kajian ini dapat ditemukan pola dalam ketakberaturan pembentukan jamak taksir. Dengan kata lain, penelitian ini menjadi penting dilakukan untuk memetakan pola-pola takberaturan dalam pembentukan jamak taksir, yang akan difokuskan pada aspek fonologis dan semantis. Ada dua hal yang harus dicermati dalam konteks ini, yaitu pola pada bentuk singular dan pola pada bentuk plural. Artinya, yang menjadi fokus perhatian, adalah polapola fonologis pada bentuk singular, yang akan menjadi pola apa pada bentuk plural. Demikian pula dengan aspek semantisnya. Unsur semantis apa yang ada pada bentuk singular sehingga menghasilkan pola tertentu pada bentuk plural.

\section{METODE}

Kajian ini bersifat sederhana, tetapi memerlukan kecermatan yang tinggi untuk dapat menemukan ciri-ciri atau indikator bersama dari semua nomina yang ada dalam sumber data. Kecermatan itu diperlukan untuk menemukan pola fonologis yang ajeg dari sejumlah perubahan itu. Oleh karena itu, metode yang tepat untuk kepentingan kajian ini adalah memanfaatkan rancangan kualitatif dengan metode penelitian observatif deskriptif. Observasi yang tajam dan cermat terhadap data akan menghasilkan gambaran tentang korespondensi bentuk singular-plural yang--sebenarnya--dapat diramalkan seperti bentuk regular. Artinya, ketika misalnya disebutkan bentuk singularnya berpola fa'lun atau $\mathrm{CaCC}$, maka bentuk pluralnya sudah dapat diramalkan berpola $\mathrm{CuCu}: \mathrm{C}$, jika ia termasuk dalam klaster makna nomina kongkrit. Demikian seterusnya, pada pola singular lainnya.

Di dalam morfologi Arab, yang harus menjadi fokus perhatian adalah akar kata yang berupa triliteral konsonan yang diberi simbol C. Sebagian besar kata dalam bahasa Arab berasal dari akar triliteral konsonan itu, sehingga disebut $\mathrm{C} 1 \mathrm{C} 2 \mathrm{C} 3$. Sebagai contoh, kata /kita:b/, berasal dari akar /k t b/. Artinya
C1-nya diisi oleh konsonan /k/, C2-nya diisi oleh konsonan /t/, dan C3-nya diisi oleh konsonan /b/. Pola pada bentuk singular kata /kita:b/ adalah /fi' a:1/ atau /C1iC2a:C3/, yang berubah menjadi pola /C1uC2uC3/ pada bentuk plural, yaitu /kutub/

Korpus data penelitian ini adalah semua ism yang ada dalam entri alif hingga kha' dalam kamus ArabInggris yang disusun oleh Hans Wehr [11] khususnya ism dengan jamak taksir. Kamus itu menjadi pilihan sumber data dalam penelitian ini, karena merupakan kamus yang biasa digunakan untuk kepentingan perkuliahan di Prodi Sastra Arab FIB UAI.

Jumlah data berupa ism dari entri alif hingga kha' adalah 728 ism. Ism yang dimaksud adalah yang memiliki jamak taksir dan bukan yang mendapat prefiks / $/$ /. Riset ini sengaja tidak memasukkan ism berprefiks / / / karena bentuk yang demikian memiliki karakteristik tersendiri, yang berbeda dan unik dari ism tanpa prefiks itu. Dari korpus data yang berjumlah 728, hanya 206 kata singular dan jamak taksirnya yang akan dijadikan sampel, yaitu yang berpola fa'lun, fi'lun, fi'latun, fi'a:lun, fu'latun, fa'alun, dan fa'latun. Berikut rinciannya,

Tabel 1 Sampel data.

\begin{tabular}{|c|c|c|}
\hline No. & $\begin{array}{l}\text { Pola pada bentuk } \\
\text { singular }\end{array}$ & Jumlah kata \\
\hline 1. & فَعْلَ & 78 \\
\hline 2 & 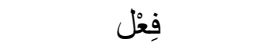 & 45 \\
\hline 3 & فُعُلة & 32 \\
\hline 4 & فِعْلة & 28 \\
\hline \multirow[t]{2}{*}{5} & فِعال & 23 \\
\hline & jumlah & 206 \\
\hline
\end{tabular}

Secara keseluruhan, ada 25 pola pada bentuk singular yang diperoleh dari 5 entri yang disebutkan di atas. 7 pola yang menjadi sampel dalam kajian ini adalah jumlah teratas yang kemunculannya ada pada setiap entri.

Pada kajian ini, data berupa kata dengan pola yang telah disebutkan di atas akan dianalisis dengan beberapa tahapan, yaitu

1. Mencermati setiap pola fonologis bentuk tunggal yang berubah menjadi pola fonologis tertentu pada bentuk pluralnya, kemudian melihat maknanya.

2. Membuat klasifikasi kluster makna dari setiap pola yang sudah dicermati pada poin 1 . 
3. Klaster makna yang dimaksud akan diklasifikasi berdasarkan kelas kata atau kategori gramatikal, karena istilah ism yang menjadi sampel, jika merujuk pada kategori gramatikal primer dapat berupa nomina, adjektiva, numeralia, pronomina, dan adverbia.

4. Menganalisis setiap pola pada bentuk singular dan menjadi pola tertentu pada bentuk plural, dengan memperhatikan klaster makna. Jika kecenderungan bentuk plural mengarah pada pola tertentu secara dominan, dapat dijelaskan bahwa pola itu yang biasanya berlaku. Jika terdapat perbedaan pola dari sejumlah pola yang dominan, maka langkah yang dilakukan adalah melihat kecenderungan makna dari pola itu. Demikian seterusnya.

\section{HASIL DAN PEMBAHASAN}

\section{Pola Fa'lun pada Singular}

Seperti tertulis pada Tabel 1, ada 78 ism yang berpola fa'lun dalam sampel data, yang diambil dari entri alif hingga kha' dalam kamus Arab-Inggris Hans Wehr [11]. Pola fa'lun ini memiliki delapan pola pada bentuk pluralnya, yaitu

\begin{tabular}{|c|c|c|}
\hline & فَعَال & $/ \mathrm{fa}$ a:1/ : 4 kata \\
\hline & فُفُوُل & /fu'u:1/ : 35 kata \\
\hline & ل فِفِعَال & /fi'a:1/ : 3 kata \\
\hline & أَفْعَال & /af'a:1/ : 32 kata \\
\hline & 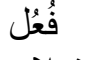 & /fa'ul/ : 1 kata \\
\hline & فِ فِعلان & /fi'la:n/ : 1 kata \\
\hline & 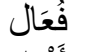 & /fa'a:1/ : 1 kata \\
\hline & أَفْعُل & /af'ul/ : 1 kata \\
\hline
\end{tabular}

Dari delapan pola tersebut, pola فُعُول /fu'u:1/ (35 kata) dan أفَْْال /af'a:1/ (32 kata) menempati angka tertinggi pada bentuk plural. Selebihnya, masingmasing pola hanya ditemukan kurang dari lima kata. Jika dicermati aspek fonologisnya, didapati kecenderungan bahwa pola fa'lun pada bentuk singular akan berubah menjadi fu'u:lun pada bentuk plural apabila memenuhi consonant order sebagai berikut.

Tabel 2. Consonant order pola fa'lun

\begin{tabular}{|c|c|c|c|c|}
\hline Contoh kata & C3 & $\mathrm{C} 2$ & $\mathrm{C} 1$ & No. \\
\hline & & $\begin{array}{l}\text { Plosif } \\
\text { voiceless }\end{array}$ & $\begin{array}{l}\text { Frikatif } \\
\text { voiceless }\end{array}$ & 1 \\
\hline 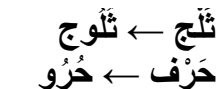 & & $\begin{array}{l}\text { Lateral } \\
\text { Drill }\end{array}$ & & \\
\hline 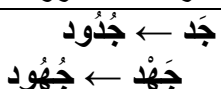 & & $\begin{array}{l}\text { Plosif } \\
\text { Frikatif }\end{array}$ & Afrikat & 2 \\
\hline
\end{tabular}

\begin{tabular}{|c|c|c|c|c|}
\hline Contoh kata & C3 & $\mathrm{C} 2$ & $\mathrm{C} 1$ & No. \\
\hline جَرْم ـ جُرُوم & & Drill & & \\
\hline بَبْر ـ بَبُور & & Plosif & Plosif & 3 \\
\hline بَزْر ـ بُبزور & & Frikatif & & \\
\hline
\end{tabular}

Tabel 2 menjelaskan urutan konsonan yang menyusun kata yang terdiri dari $\mathrm{C} 1 \mathrm{C} 2 \mathrm{C} 3$. Hasil pengamatan pada korpus data yang ada menunjukkan bahwa kecenderungan yang ditemukan mengarah pada susunan yang demikian. Pada nomor 1, kata yang terdiri dari bunyi frikatif atau bunyi geseran yang tak bersuara, diikuti oleh bunyi plosif takbersuara merupakan kata yang paling banyak dijumpai pada perubahan pola fa'lun menjadi pola fu'u:lun. Artinya, apabila menemukan kata dengan urutan konsonan seperti pada tabel, dapat diramalkan bahwa bentuk pluralnya akan berpola fu'u:lun.

Adapun untuk pola fa'lun yang berubah menjadi pola af'a:lun pada pluralnya, diperoleh temuan yang memperlihatkan konsistensi secara menyeluruh pada data dari entri alif hingga kha' ini. Apabila C2 pada bentuk singular diisi oleh konsonan /waw/ atau /ya/, semua kata dalam data menunjukkan bentuk pluralnya berpola af'a:lun, kecuali 1 kata, yaitu تَوْب /tsawb/ yang berubah menjadi /tsiya:b/. Dengan kata lain, satu kata itu tidak mengikuti pola af'a:lun, tetapi menjadi fi'a:lun. Akan tetapi, untuk C2 yang diisi oleh konsonan /ya/, ditemukan 1 bentuk plural memiliki pola lain yaitu fu'u:lun. Fenomena ini sejalan dengan apa yang telah dijelaskan oleh Pinker pada subbab sebelumnya tentang keteraturan di dalam ketakberaturan, walaupun tetap saja, selalu ada pengecualian. Enam pola lainnya pada bentuk plural, tidak memperlihatkan jumlah kata yang memadai untuk digeneralisir.

Jika dilihat dari aspek semantis, secara umum belum ditemukan kecenderungan yang mengarah pada satu klaster makna yang identik. Semua kata yang berpola fa'lun pada bentuk singular, baik yang berubah menjadi pola fu'u:lun maupun yang berubah menjadi af'a:lun pada bentuk plural, menunjukkan makna yang beragam. Ada yang menunjukkan bilangan, nomina abstrak, anggota badan, perlengkapan, nomina verbal dan kualitas, serta benda angkasa.

\section{Pola Fi'lun pada Singular}

Kami menemukan 45 kata singular yang berpola fi'lun dari korpus data alif hingga kha'. Ada beberapa pola pada bentuk pluralnya, yaitu

$$
\text { laf'a:lun/ : } 33 \text { kata }
$$




$\begin{array}{ll}\text { Ifu'u:lun/ } & \text { :6 kata } \\ \text { |fu'la:n/ } & : 1 \text { kata } \\ \text { laf'a:lun dan fu'u:lun/ } & : 5 \text { kata }\end{array}$

Consonant order pada bentuk plural dengan pola laf'a:lun/ memperlihatkan keragaman pola fonologisnya, sehingga tidak dapat ditarik kecenderungannya. Sebagian besar data justru menjelaskan bahwa pola fi'lun pada bentuk singular akan dapat dengan mudah diprediksi berubah menjadi pola af'a:lun pada bentuk pluralnya. Perhatikan contoh berikut!

\begin{tabular}{|c|c|}
\hline 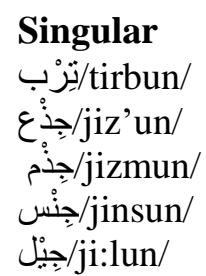 & 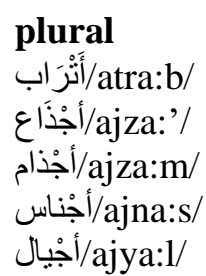 \\
\hline
\end{tabular}

Yang menjadi perhatian justru pada bentuk plural dengan pola fu'u:lun. Enam kata yang memperlihatkan bentuk plural dengan pola itu, menunjukkan bahwa C2-nya diisi oleh konsonan velarisasi. Berikut adalah contohnya.

$$
\begin{array}{ll}
\text { /khasm/ } \rightarrow & \text { /khusu:m/ } \\
\text { /khatb/ } \rightarrow & \text { /khutu:b/ } \\
\text { /haql/ } \rightarrow & \text { /huqu:1/ }
\end{array}
$$

Ini dapat menjadi asumsi bahwa konsonan velar yang mengisi $\mathrm{C} 2$ pada bentuk singular akan menjadi indikator untuk mengubah bentuk pluralnya mengikuti pola fu'u:lun.

\section{Pola Fi'latun pada Singular}

Ada 28 kata yang berpola fi'latun pada bentuk singular dalam korpus data. 27 kata memperlihatkan pola $f i^{\prime} a: l$ pada bentuk pluralnya, sedangkan satu kata lain, berpola fa'a:la Fenomena ini menunjukkan bahwa pola fi'latun dapat diprediksi polanya pada bentuk plural, walaupun memang belum dapat dijadikan kesimpulan akhir, karena jumlah data yang belum menyeluruh, meliputi semua entri dalam kamus. Akan tetapi, ini dapat dijadikan bahan untuk kajian selanjutnya.

$$
\begin{aligned}
& \text { Singular Plural }
\end{aligned}
$$

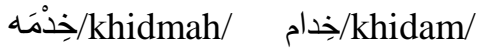

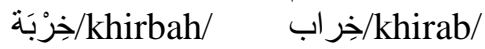

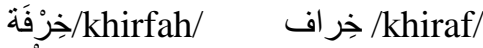

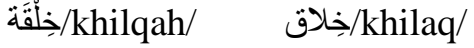

\section{Pola Fu'latun pada singular}

Bentuk singular yang berpola fu'latun ditemukan sebanyak 32 kata. Data memperlihatkan bahwa semua kata yang berpola itu, berubah menjadi fu'alun pada bentuk pluralnya. Ini dapat dijadikan

\begin{tabular}{|c|c|}
\hline 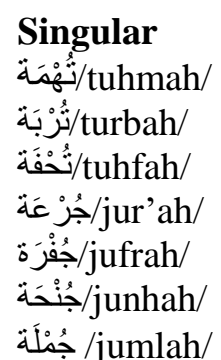 & 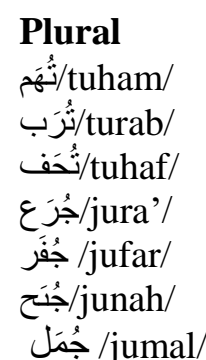 \\
\hline
\end{tabular}
asumsi awal, bahwa ism singular yang berpola fu'latun, akan mudah diprediksi bentuk pluralnya, yaitu berpola fu'a:lun.

\section{Pola Fi'a:Iun pada Singular}

Pola fi'a:lun pada bentuk singular memperlihatkan keragaman pola pada bentuk pluralnya. Dari 23 kata yang masuk dalam kategori ini, ditemukan 8 pola pada bentuk pluralnya, yaitu

$$
\begin{aligned}
& \text { /fa'a:'il/ } \\
& \text { /af'a:1/ } \\
& \text { /fu'ul/ } \\
& \text { /fu'la:n/ } \\
& \text { /af'ilah/ } \\
& \text { /fu''a:1/ } \\
& \text { /fa'i:1/ } \\
& \text { /af'ilah/ }
\end{aligned}
$$

Jika dilihat consonant ordernya, belum dapat dirumuskan untuk mengarah pada sebuah pola yang dominan. Begitu pula jika dicermati dari keunikan pada C2nya yang berupa konsonan tertentu. Artinya, aspek fonologis pada bentuk singular dengan pola ini, masih bersifat iregular. Akan tetapi, sangat dimungkinkan jika jumlah data ditambah hingga entri akhir /ya/, kecenderungan pola tersebut akan diperoleh.

\section{KESIMPULAN}

Jamak taksir dalam bahasa Arab tergolong dalam kategori perubahan inflektif yang iregular, karena tidak memiliki kaidah atau aturan yang berlaku umum untuk semua kata yang semisal. Namun, ketiadaan kaidah bukan berarti tidak memiliki aturan sama sekali, karena pada hakikatnya dalam setiap ketidakberaturan, ada semacam pola yang teratur, yang kehadirannya memang kurang begitu diperhatikan. Pola-pola beraturan dalam ketakberaturan itu memang lebih detail, lebih 
spesifik, dan lebih membutuhkan kecermatan untuk merumuskannya. Namun, kenyataan itu menjadi bukti bahwa apa yang dipaparkan oleh HuangPinker [8] itu benar.

Dari 5 pola pada bentuk singular yang menjadi fokus perhatian dalam kajian ini, dapat dijelaskan bahwa aspek fonologis memiliki peran besar untuk menentukan pola pada bentuk singular. Secara umum, lima pola pada bentuk singular akan menjadi pola tertentu pada bentuk pluralnya, seperti berikut ini.

1. Fa'lun cenderung berubah menjadi pola af'a:lun dan fu'u:lun dengan syarat consonant order yang spesial

2. Fi'lun cenderung berubah menjadi pola af'a:lun, dan berubah menjadi fu'u:lun jika C2 diisi oleh konsonan velarisasi

3. Fi'latun cenderung berubah menjadi pola fi'a:lun

4. Fu'latun cenderung berubah menjadi pola fu'a:lun

5. Fi'a:lun belum dapat dirumuskan kecenderungan polanya.

Adapun dari aspek makna, data yang ada dalam kajian ini masih belum memberikan konstribusi yang signifikan untuk turut merumuskan pola pada bentuk plural.

Kajian ini akan menjadi komprehensif, apabila korpus data meliputi semua entri dalam kamus, sehingga jumlah data menjadi lebih besar. Dengan demikian, rumusan pola akan lebih representatif. Selain itu, kajian ini dapat dikembangkan dengan membuat eksperimen pada responden, baik pada penutur jati, maupun pada peminat bahasa Arab.

\section{REFERENSI}

[1] I. Berent, S. Pinker and J. Shimron, "The Nature of Regularity and Irregularity: Evidence from Hebrew Nominal Inflection," Journal of Psycholinguistic Research, vol. 31, no. 5, 2002.
[2] S. Pinker, The Language Instinct, How The Mind Creates Language, New York: Basic Books, 1997.

[3] S. Pinker, Words and Rules, New York: Basic Book, 1999.

[4] G. Runblad, "Regularity and Regular Irregularity," Januari 2000. [Online]. Available: https://www.researchgate.net/publication/2570 02248_Regularity_and_Regular_Irregularity.

[5] P. Royle, G. Beritognolo and E. Bergeron, "Regularity, sub-regularity and irregularity in French acquisition," Oktober 2012. [Online]. Available: https://www.researchgate.net/ publication/261946918_Regularity_subregularity_and_irregularity_in_French_acquisi tion.

[6] J.P Stemberger, "Phonological and Lexical Constraint on Morphological Processing," in Morphological Aspects of Language Processing, NJ, Hillsdale, 2008, pp. 247-267.

[7] "Morphology in Language Production with Special Reference to Connectionism," in The Handbook of Morphology, Oxford, Blackwell, 1998, pp. 428-425.

[8] Y. T. Huang and S. Pinker, "Lexical semantics and irregular inflection," Language and Cognitive Processess, pp. 1-51, 2010.

[9] E. Shimkin and Y. Tobin, The Regularity of 'Irregular' Verbs and Nouns in Eglish, Amsterdam: John Benjamins, 2013.

[10] Liliana, "The Regularity of the English Irregular Verbs Seen in the Rule of About. [Bacelhor Thesis]," English Departement Universitas Santa Dharma, Yogyakarta, 2015.

[11] H. Wher, A Dictionary of Modern Written Arabic, London: Harrap, 1954. 